\title{
Management and Development of Talented Employees in the Global World
}

\author{
Martin Kursch ${ }^{1}$ and Jaroslav Veteska*,1 \\ ${ }^{1}$ Charles University in Prague, Faculty of Education, Department of Andragogy and Educational \\ Management, Myslíkova 7, 11000 Prague 1, Czech Republic
}

\begin{abstract}
.
Research background: The study focuses on the search for talented individuals depending on the size and form of organizations in the Czech Republic.

Purpose of the article: The article answers the question where organizations are looking for talented individuals in the Czech Republic in the era of digitization and Industry 4.0. It also reveals whether different forms of organization and their size play a role in finding talented individuals.

Methods: A representative sample of 301 talent management organizations found whether the search for talented individuals depends on the size of private organizations and whether the form of the organization affects its application. The study is part of a very extensive research completed in 2018 dealing with the effectiveness of talent management methods in the Czech Republic.

Findings \& Value added: It produces specific results related to the way talented individuals are found in small, medium, and large private organisations and public organisations. The result is to determine the dependency between size, form of organization and search for talented individuals. The study also points to the fact that the "talent pool" method is independent of seeking talent within an organisation or in the labour market. The study covers a wide range of organisations, including public organisations, which are neglected in most current research.
\end{abstract}

Keywords: talent management; form of organization; public and private organizations; global world; employee development

JEL Classification: $A 12 ; O 15 ; O 31$

* Corresponding author: jaroslav.veteska@pedf.cuni.cz 


\section{Introduction}

At present, we often encounter new requirements for the development and training of workers, related to the advent of new technologies and globalisation [1]. New competences are emerging, pointing out the need for fundamental changes in this area $[2,3,4]$. We could argue that defining the postmodern neoliberal era as a time with progressive dynamism and the preponderance of discontinuous change is more of a phrase and is not based on demonstrable arguments [5].

However, despite all these objections, we think that the use of new technologies in particular overcomes distance barriers, and progressive globalisation, in turn, cultural and economic barriers, that is, processes in the world are accelerating and humanity is indeed facing new problems [6] and challenges in the field of human resources management [7, 16, 24]. In defining new requirements for the development and training of workers [8]. It is an effective transfer of knowledge and skills, the development of an individual and the realization of the principles of a lifelong learning [9, 11, 22]. In the context of globalisation and digitalisation, these fundamental principles are determined by a new paradigm in the field of economy (Industry 4.0) [14, 17, 18], but also in the field of development and education of people (Education 4.0) [15,21]. Digitalization and virtualization in the era of the Industry 4.0 adjust the nature of finance and interaction between market participants [23].

The modern industrial revolution is a natural result of all previous technological developments, embedded in social and economic systems. The concept of Industry 4.0 is based on the creation of value through the close interaction of all economic agents through digitalization [23]. A new model of educational robotics is emerging as an innovative educational technology [16].

The strategic management of talented workers in organisations $[10,20]$ is currently proving to be a competitive advantage and a tool for the prosperity [21] and development of the organisation $[2,5]$. Multinational enterprises (MNEs) that originate from emerging economies are rapidly expanding beyond national borders, yet they face major challenges in developing and deploying managerial competencies to lead international operations [24].

In practice, talent management is more a tool for searching talented individuals for their development, deployment and maintenance [19]. This tool has the task of streamlining work with talented people and thus supporting the achievement of the organization's goals in line with its strategy to achieve competitive advantage [4]. However, the use of talented people in public organizations is largely ignored, but most of them do not strive to achieve a competitive advantage, but above all to meet the goals of both partial, overall and strategic [5].

Working with the talented public organizations is neglected and is only a subject of research $[3,9]$. It is precisely who are one of the few who are engaged in talent management in government agencies in the US [13]. We have also included public organizations in the research project within the Czech Republic. The situation in the field is, however, very unclear. On the one hand, most organizations realize talent management on their own, and the results are often very questionable [2]. Cappelli's research [3] shows that about two-thirds of US companies do not plan anything for their talented ones [9]. Our article focuses on the search for talented individuals depending on the size and form of organizations in the Czech Republic in the beginning of the era of digitization $[12,25]$.

\section{Methodology and research sample}

The sample was selected from the population of all organizations that have more than 5 employees and their headquarters in the Czech Republic. The population is made by all organizations in the Czech Republic with more than 5 employees. All the parameters of the 
performed research are presented in Table 1. A suitable questionnaire was selected by the research method, including questions related to the effectiveness of talent management methods. $^{12}$

Table 1. Resulting parameters of quantitative research (own processing)

\begin{tabular}{|c|c|c|c|c|}
\hline & Private25 & $\begin{array}{c}\text { Private25- } \\
\mathbf{2 5 0}\end{array}$ & Private250 & Public \\
\hline Population & 52212 & 17034 & 1468 & 12762 \\
\hline Usable_mail/db & 24300 & 12300 & 739 & 2450 \\
\hline Usable_mail/populace & $46.54 \%$ & $72.21 \%$ & $50.34 \%$ & $19.20 \%$ \\
\hline Summary/db & 24300 & 12300 & 739 & 2450 \\
\hline Random pattern & 2430 & 1230 & 739 & 2450 \\
\hline Pattern/usable_mail & $10.00 \%$ & $10.00 \%$ & $100.00 \%$ & $100.00 \%$ \\
\hline Sent_summary & 2430 & 1230 & 739 & 2450 \\
\hline Reminded & $1 \times$ & $1 \times$ & $2 \times$ & reminded \\
\hline Returned & 313 & 174 & 194 & 119 \\
\hline Date of execution & $8.7 .2014-$ & $10.11 .2014-$ & $22.4 .2014-$ & $5.1 .2015-$ \\
\hline Published e-mail \\
returned & 10.11 .2014 & 5.1 .2015 & 8.7 .2014 & 15.2 .2015 \\
\hline Returnability & 177 & 91 & 130 & 80 \\
\hline Use TM & $\mathbf{1 2 . 8 8 \%}$ & $\mathbf{1 4 . 1 5 \%}$ & $\mathbf{2 6 . 2 5 \%}$ & $\mathbf{4 . 8 6 \%}$ \\
\hline Ratio use/returned & $\mathbf{3 0 . 6 7 \%}$ & $\mathbf{2 9 . 3 1 \%}$ & $\mathbf{5 0 . 0 0 \%}$ & $\mathbf{4 7 . 9 0 \%}$ \\
\hline
\end{tabular}

Note:

Private_25 = organizations with less than 25 employees; Private_25-250= organizations from 25 to 250 employees; Private_250 = organizations with more than 250 employees; Public = public organizations of all sizes; Population = the total number of organizations targeted by the criteria (number of employees); Usable_mail/db = the number of organizations that can be reached from the database (indicated by e-mail); Usable_mail/population = ratio applicable organizations to population (percentage); Summary/db = total number of useful contacts; Random pattern = selected samples of the population, a random $10 \%$ if there is a large population, $100 \%$ for small populations; Pattern/usable_mail = ratio selected random contacts (percentage); Sent_summary $=$ real number of organizations, where survey was sent; Reminded $=$ number of reminders during research; Returned = the number of returned useful answers; Date of execution = date of research and its duration; Published E-mail returned = the number of returnees who identified via e-mail; Returnability = percentage ratio of returned answers to a number of those where survey was sent; Use TM = the number of organizations that work with talents;

\footnotetext{
${ }^{1}$ The concept of population (or subpopulation) is used in statistical meaning and means the basic set (or part thereof), see eg. Kursch [9].

${ }^{2}$ The most important aspect for all quantitative research was to get the questionnaire into the right hands. In order the answers were valid, it was necessary to be sure that the relevant employee is either a human resource staff member dealing with talent management or a member of the management team working with talented or employees in the organization, or a representative of leadership familiar with this issue. Failure to do so may cause distortion. This objective was achieved by pre-research and subsequent provision of controversial parameters [8].
} 
Ratio use TM/returned $=$ proportion of organizations that deal with talent management to returned answers;

Due to the relatively high returns, research can be considered successful, and this can be confirmed in terms of the quality of returns, parameters, and data consistency. In addition, a comparison of sample representativeness was made based on return e-mail addresses with the distribution of the business sector in the population. The results are shown in Table 2.

Table 2. Verification of sample representativeness - economic entities by business sector (only private organizations), source: $\mathrm{CSO}-$ own processing ${ }^{3}$

\begin{tabular}{|c|c|c|c|c|c|c|c|}
\hline Industry group & $\stackrel{5}{0}$ & 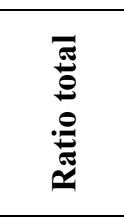 & 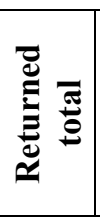 & 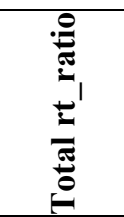 & 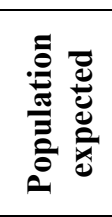 & 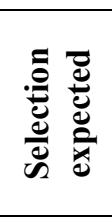 & 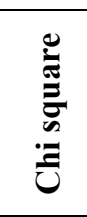 \\
\hline $\begin{array}{l}\text { Agriculture, } \\
\text { hunting and } \\
\text { forestry }\end{array}$ & 3207 & $4.9 \%$ & 12 & $3.0 \%$ & 3207 & 19.62 & 2.96 \\
\hline $\begin{array}{l}\text { Mining and } \\
\text { quarrying }\end{array}$ & 142 & $0.2 \%$ & 2 & $0.5 \%$ & 142 & 0.87 & 1.47 \\
\hline Production & 14206 & $21.8 \%$ & 101 & $25.4 \%$ & 14206 & 86.93 & 2.28 \\
\hline $\begin{array}{l}\text { Manufacturing } \\
\text { industry }\end{array}$ & 1417 & $2.2 \%$ & 10 & $2.5 \%$ & 1417 & 8.67 & 0.20 \\
\hline $\begin{array}{l}\text { Production and } \\
\text { distribution of } \\
\text { electricity, gas, } \\
\text { water, heat }\end{array}$ & 1410 & $2.2 \%$ & 4 & $1.0 \%$ & 1410 & 8.63 & 2.48 \\
\hline Building & 7822 & $12.0 \%$ & 45 & $11.3 \%$ & 7822 & 47.86 & 0.17 \\
\hline Trade & 15275 & $23.5 \%$ & 97 & $24.4 \%$ & 15275 & 93.47 & 0.13 \\
\hline Transport & 3832 & $5.9 \%$ & 10 & $2.5 \%$ & 3832 & 23.45 & 7.71 \\
\hline Services & 16265 & $25.0 \%$ & 109 & $27.4 \%$ & 16265 & 99.53 & 0.90 \\
\hline Other & 418 & $0.6 \%$ & 1 & $0.3 \%$ & 418 & 2.56 & 0.95 \\
\hline Financial services & 832 & $1.3 \%$ & 6 & $1.5 \%$ & 832 & 5.09 & 0.16 \\
\hline $\begin{array}{l}\text { Research and } \\
\text { development }\end{array}$ & 215 & $0.3 \%$ & 1 & $0.3 \%$ & 215 & 1.32 & 0.08 \\
\hline SUMMARY & 65041 & $100.0 \%$ & 398 & $100.0 \%$ & 65041 & 398.00 & 19.50 \\
\hline
\end{tabular}

Note: Total $=$ the absolute frequency of organizations in the population; Ratio total $=$ relative frequency in the population organizations; Returned total $=$ number of returned answers; Total rt_ratio = relative number of returned answers; Population expected = expected frequency in the population (equal to the absolute); Selection expected = expected frequency in the sample returned answers; Chi square= partial compliance calculations (Chi-squared test).

${ }^{3} \mathrm{CSO}$ - Business subjects by legal form and number of employees (ref: ORG5021UU_KR), $31^{\text {st }}$ Dec 2013. 


\section{Calculation of representativeness of pattern with Chi-squared test}

$n_{o}$ - expected frequency

$n_{e}$ - experimental frequency

Test criteria:

$$
\begin{gathered}
\chi^{2}=\sum\left[\left(n_{e i}-n_{o i}\right)^{2} / n_{o i}\right]= \\
=(12-19,62)^{2} / 19,62+(2-0,87)^{2} / 0,87+(101-86,93)^{2} / 86,93+(10-8,67)^{2} / 8,67+(4- \\
8,63)^{2} / 0,87+(45-47,86)^{2} / 0,87+(97-93,47)^{2} / 0,87+(10-23,45)^{2} / 0,87+(109-99,53)^{2} / 0,87+ \\
(1-2,56)^{2} / 0,87+(6-5,09)^{2} / 0,87+(1-1,32)^{2} / 0,87=\mathbf{1 9 , 5}
\end{gathered}
$$

Degrees of freedom:

$$
v=m-1=11
$$

Critical values corresponding levels $\alpha=0,05$ and $\alpha=0,1$ given degree of freedom:

$$
\begin{aligned}
& \chi^{2} 0,95(11)=19,677 \\
& \chi^{2} 0,90(11)=17,276
\end{aligned}
$$

We find:

$$
\chi^{2}<\chi^{2} 0,95(11)
$$

$\Rightarrow$ the difference between the measured and expected frequency is not statistically significant at the 0,05 level of significance.

Conclusion: The sample is considered representative and is statistically not significantly different from the population.

It can be stated that even the representativeness of the returned sample of responses from private organizations is satisfactory, since the distribution of the business sectors in the sample corresponds approximately to the distribution of the sectors of the population. Also, Chi-squared test shows that there is no significant difference in the distribution of sectors in the population and distribution sectors in returned organizations. For public organizations are dominantly prevalent in the population schools (unless you count church organizations, municipalities and municipals), as well as in our sample returned answers, but we cannot make a conclusion on the representativeness of public organizations part due to small sample. ${ }^{4,5}$

\section{Results of sub-research}

A part of the great original research tried to answer the research problem, which is summed up by the following question: how is the search for talent in different forms and sizes of

\footnotetext{
${ }^{4}$ It also owners associations, endowment funds, foundations, associations (federation, union, society, club, etc.), an organizational unit of the association, an association of legal entities, hunting communities, etc., have not been taken into account as a public employee organizations and are not subject to our research.

${ }^{5}$ Our database has 2,450 usable email contacts, while $98 \%$ of them were schools (elementary, middle, high).
} 
organizations approached? We wanted to find out whether organizations are looking for talented individuals in the labour market or within the organization. What influence does the size and form of the organization play and whether the search for talent is influenced by the fact that there is a special talent development program in the organization (talent pool method). Subsequently, supporting hypotheses were formulated, which the research sought to confirm or refute.

\section{Hypothesis 1: Smaller private organizations are looking for talent in the labour market more than large private organizations.}

This hypothesis has been confirmed. Large organizations (more than 250 employees) have the phenomenon that $42 \%$ of these organizations, using talent management, say they are looking for talent only within the organization. This ratio is changing rapidly, with only $11 \%$ of small, medium-sized organisations looking for the talented inside of them. For public organisations, the ratio is $23 \%$, where the financial cost of finding the talented at labour market is likely to play a role.

We can therefore conclude that large private organizations can afford to look for talent only within the organization primarily because of their size, and precisely the introduction of robust formal talent management programs. So, we confirm the hypothesis. While such a finding seems logical, the benefit is its confirmation. With the size of the organization, the potential for selecting talent within the organization increases, which with the correct implementation of the talent management program can lead to great positive effects, due to lower selection costs and higher motivation of the talented themselves.

\section{Hypothesis 2: Private organisations seek out the talented more only in the labour market than public organisations.}

This hypothesis has not been confirmed. The ratio of search for the talented only in the labour market is $5 \%$ for public organisations and $6 \%$ for private organisations. So, the difference is not significant, and we certainly cannot confirm the hypothesis. This is probably since for both private and public organizations, finding the talented only in the labour market is quite expensive and does not fully exploit the possible potential of the organization.

Hypothesis 3: Organizations that say they are looking for the talented only within the organization use a special talent development program (and inclusion in talent pools) as a method of talent development.

This hypothesis does not apply. Private organisations dedicated to talent management are looking for the talented within the organisation and in the labour market (69\%), as well as public organisations (70 \%). A full $23 \%$ of organisations say they only look for the talented within the organisation. Interestingly for large organizations, $42 \%$ of them are looking for talented exclusively within the organization. This finding could be interpreted as having enough of the talented within the organization for large organizations, especially because of the large number of employees. The cost of hiring a new person is high, so, for example, corporations prefer to find the talented only within an organization.

What about "talent pools"? For organizations that seek the talented only inside, the predominant method of development ( $22 \%$ for large companies) is certainly not a special talent pools program. Therefore, finding the talented only within an organization is not related to the effectiveness of the "talent pools" method. Therefore, we cannot confirm the hypothesis. With deeper reflection, we can then conclude that special programs for developing the talented and assigning them to "talent pools" are independent methods of attracting the talented inside or outside the organization. This method is therefore rather a 
method focusing on selected talented individuals, regardless of where they were selected from.

\section{Discussion}

During our research, we have uncovered some other interesting findings:

1. Talent management is increasingly used in organizations in the Czech Republic (compared to Horváthova [17] research from 2009, it has been shown to increase the minimum ratios of use of talent management in private organizations).

2. Talent management is only formal in a few cases, which does not mean that the talented are not worked with. Formalization of talent management probably plays an important role especially for large organizations for many reasons (e.g. already established support departments, availability of resources, from the need for a systematic approach due to the size of the organization). However, small but also public organisations also work with the talented, and organisations, although informally, really support the talented and use the methods available to do so.

3. Talent management methods are not uniform, classical methods of human resources management are mostly used, research has not shown the use of any special, unusual, or unknown methods for identifying, developing and maintaining the talented. In each question concerning method research, there was scope for expression and indication of methods or instruments other than those mentioned, no organisation indicated a specific procedure, instrument, or method [11]. Only methods that could be included in our specified groups (development centre, project work, personal tasks, shading, interview with supervisor and others) were mentioned. It also points to a small activity in the field of knowledge of talent management, its new trends and the area of new methods aimed at the talented. Professional publications, magazines, universities should play the role of education here, but in the Czech Republic such activities are still rather rare.

4. In the age of ongoing digitization and in the age of industry 4.0, talent management is a prerequisite for success, as working with digital technologies is challenging to maintain "trends" and reflect constant change and new ways of thinking. From this we can deduce the real need for talented individuals in this area. Organizations should therefore devote their efforts not only to finding talented individuals in the labour market, but also to finding within their own organization and thus improving the identification, development and retention of those talented individuals. One way to achieve this is to set up the right talent management program.

\section{Conclusions}

Our research answered a research question: Where do organizations look for the talented? Organizations are looking for the talented inside the organization and in the labour market. However, we did not find major differences according to the form of organizations. We found that larger private organizations are looking for the talented more frequently "only inside" than small and medium-sized ones. This implies a greater need for quality talent management programs for large organizations. We also found that these programs are not based primarily on talent pools, but also on other methods for working with the talented.

For large organizations, you can see the positive effect of talent management as a tool for finding the talented within the organization. There are usually enough talented people mainly 
because of the large number of employees. The cost of hiring a new person is high, which is why corporations and large businesses prefer to find the talented inside of the company.

Organizations think about methods of selecting talented people, on the one hand, they evaluate their success but also their price. They therefore intuitively view methods through their effectiveness, but in most cases do not measure them. It can be seen that methods such as the assessment centre are mainly used by large organizations, but all organizations also rely on other methods that specifically suit them in process of selecting identification methods. It can be said that the choice of methods also depends on the creator of the talent management program or on the leaders (preference based on intuition).

In the era of Industry 4.0 and the era of digitization, finding talented individuals is a key activity that brings a long-term competitive advantage. Our findings may prompt talent management organizations to think about the possibility of more frequent search for the talented within the organization and harnessing the potential of talented people who have been successful in the organization for a long time and have not yet been identified.

\section{References}

1. Cascio, W. F., \& Boudreau, J. W. (2016). The search for global competence: From international HR to talent management. Journal of World Business, 51(1), 103-114.

2. Araujo, A. F., \& Machado Araujo, J. (2018). New education and school work: horizon and polarities of an educational vision. TEORIA DE LA EDUCACION, 30(1), 201-216..

3. Alferaih, A. (2018). Advances in Talent Management Research: A Review of Extant Literature. In Emerging Markets from a Multidisciplinary Perspective (pp. 359-379). Springer, Cham.

4. Bowman, C., \& Hird, M. (2014). A resource-based view of talent management. Strategic talent management: Contemporary issues in international context, 71-83.

5. Dries, N. (2013). The Psychology of Talent Management: A Review and Research Agenda. Human Resource Management Journal, 23(4), 272-285.

6. Gallardo-Gallardo, E., Thunnissen, M. \& Scullion, H. (2017). A Contextualised Approach to Talent Management: Advancing the Field. International Journal of Human Resource Management. Advance online publication.

7. Farndale, E., Scullion, H., \& Sparrow, P. (2010). "The Role of the Corporate HR Function in Global Talent Management." Journal of World Business, 45(2), 161-168.

8. Havigerova, J. M. (2011). Five perspectives on talent. Prague: Grada

9. Kursch, M. (2016). Tailor Made Talent Management - Second Generation Talent Management. Prague: Czech Andragogy Society.

10. Lepak, D. P., Jiang, K., Han, K., Castellano, W. G., \& Hu, J. (2012). Strategic HRM moving forward: What can we learn from micro perspectives? International Review of Industrial and Organizational Psychology, 27, 231-258.

11. Lytras, M. D., Visvizi, A., Daniela, L., Sarirete, A. \& Ordonez de Pablos, P. (2018). Social Networks Research for Sustainable Smart Education. Sustainability, 10(9), 2974.

12. Ospennikova, A., Ershov, M., \& Ilyin, I. (2015). Educational robotics as an inovative educational technology. Social and Behavioral Sciences, 214, 18-26.

13. Oztemel, E., \& Gursev, S. (2020). Literature review of Industry 4.0 and related technologies. Journal of Intelligent Manufacturing, 31(1), 127-182. 
14. Richert, A., Shehadeh, M., Plumanns, L., Groß, K., Schuster, K., \& Jeschke, S. (2016, April). Educating engineers for industry 4.0: Virtual worlds and human-robot-teams: Empirical studies towards a new educational age. In 2016 IEEE Global Engineering Education Conference (EDUCON) (pp. 142-149). Ieee.

15. Stumbitz, B., Lewis, S., \& Rouse, J. (2018). Maternity management in SMEs: a transdisciplinary review and research agenda. International Journal of Management Reviews, 20(2), 500-522.

16. Tung, R. L. (2016). New perspectives on human resource management in a global context. Journal of World Business, 51(1), 142-152.

17. Ulrich, D., \& Smallwood, N. (2012). "What Is Talent?" Leader to Leader, 2012(63), 55-61.

18. Veteska, J., \& Kursch, M. (2018). The research on the efficiency of the methods of talent management within organizations. New Educational Review, 52(2), 28-42.

19. Collings, D. C., \& Mellahi, K. (2018). "Strategic Talent Management: A Review and Research Agenda." Human Resource Management Review, 19(4), 304-313.

20. Collings, D. G., Mellahi, K., \& Cascio, W. F. (2019). Global Talent Management and Performance in Multinational Enterprises: A Multilevel Perspective. Journal of Management, 45(2), 540-566.

21. Delery, J. E., \& Roumpi, D. (2017). Strategic human resource management, human capital and competitive advantage: Is the field going in circles? Human Resource Management Journal, 27(1), 1-21.

22. Bilan Y., Rubanov P., Vasylieva T., \& Lyeonov, S. (2019). The Influence of Industry 4.0 on Financial Services: Determinants of Alternative Finance Development. Polish Journal of Management Studies, 19(1), 70-93.

23. Meyer, K. E., \& Xim, K. (2018). Managing talent in emerging economy multinationals: integrating strategic management and human resource management. International Journal of Human Resource Management, 29(11), 1827-1855.

24. Sparrow, P., Scullion, H., \& Tarique, I. (2014). Introduction: challenges for the field of strategic talent management. Strategic talent management: contemporary issues in international context. Cambridge University Press, Cambridge, 3-35.

25. Horvathova, P. (2011). Talent management. Prague: Wolters Kluwer. 